\title{
Origin and Effect of Lateral Cracks in Oxide Scales Formed on Zirconium Alloys
}

\author{
Pia Tejland and Hans-Olof Andrén \\ Department of Applied Physics, Chalmers University of Technology, \\ SE-412 96 Göteborg, Sweden
}

Corresponding author: P. Tejland pia.tejland@chalmers.se, Phone +46 31772 3137, Fax +46.31 .7723224$

\begin{abstract}
Two varieties of Zircaloy-2, with different second phase particle (SPP) size distributions and different corrosion resistance, were oxidized in a steam autoclave. Transmission electron microscopy was used for investigation of the fine-scale lateral cracks present in the oxide scales. Crack quantification was performed and the number of cracks was correlated with the number of SPPs. A mechanism for crack formation is presented, in which the driving force is the local tensile stresses in the oxide close to the oxide/metal interface, and the initiation sites are un-oxidized SPPs located within this stress field.
\end{abstract}

Keywords: Zircaloy-2; lateral cracks; SPP; TEM

\section{Introduction}

Zirconium alloys used for fuel cladding in light water nuclear reactors are subject to oxidation in the corrosive environment of the reactor core. This oxidation has been vastly studied before, but the detailed mechanisms of the oxidation process are still not known. In attempts to learn more about the process, studies of the oxide and oxide/metal interface have been performed using transmission electron microscopy (TEM) of thin foil cross-sections as a characterization tool. Until recently these studies were technically very demanding, and only small areas could be imaged [1-7]. 
However, the advent of the focused ion beam (FIB) technique has now made it possible to prepare cross-section thin foils of high quality and relatively large area (typically $10 \times 5 \mu \mathrm{m}$ ) [8]. This means that large parts of the oxide scale can be imaged in one micrograph, making it possible to gain both a good overview and more detailed analysis [9-13].

The oxide scale on zirconium alloys consists mainly of small, columnar shaped grains (10-40 nm wide and 100-400 nm long) of monoclinic $\mathrm{ZrO}_{2}$ [10,13]. In the oxide scales on many different zirconium alloys there is a large amount of fine-scale lateral cracks parallel to the oxide/metal interface. These cracks have been studied before using techniques such as optical microscopy and scanning electron microscopy (SEM) [14-19], and they are also visible, although not discussed, in some TEM studies [20,21]. There are also a few studies where the cracks have been studied using TEM $[9,22-25]$. The occurrence of the lateral cracks has remained somewhat a mystery for many years, as no explanation could be found for how cracks could be created in this direction. In early theories cracks were instead proposed to form in the vertical direction, i.e. perpendicular to the oxide/metal interface [26]. Now, with the new FIB technique, there are new possibilities to study the cracks using TEM, and thereby gain knowledge of their role in the oxidation process.

There has been much debate on whether the cracks are really created during oxidation or if they are a result of TEM specimen preparation. However, since the cracks can also be seen in SEM studies of bulk samples, they cannot only be an effect of TEM specimen preparation but rather a real oxidation phenomenon [9]. This being said, it cannot be completely ruled out that also preparing one-sided SEM cross-sections somewhat relaxes stresses and that there is still a risk of somewhat increasing the size of the cracks during specimen preparation.

The present work is an attempt to give a more detailed description of how and why lateral cracks are formed in the oxide scale on zirconium alloys, using TEM imaging. Two Zircaloy-2 alloys with different intermetallic second phase particle (SPP) size distributions will also be compared with respect to their cracking behavior. A substantial amount of work has already been carried out recently concerning these lateral cracks. In a study by Ni et al., 3-dimensional FIB slicing was used to study the 
crack formation in oxides of different thicknesses on ZIRLO $^{\mathrm{TM}}$ (a niobium-containing zirconium alloy) [23]. Some quantification of the cracks was performed and it was confirmed that the volume fraction of cracks increases with oxide thickness. In the present study a similar quantification will be made in order to compare the two Zircaloy-2 materials, to compare materials with different oxide thicknesses, and to correlate the cracking behavior to the SPP size distribution.

Previously we have observed void and crack formation adjacent to SPPs embedded in the oxide [25], and in the present work this observation will be correlated to the crack densities in materials with different SPP distributions. Thus, this is an attempt to explain one of the mechanisms behind the well-known fact that the SPP size distribution is an important factor influencing the oxidation process [27-31].

\section{Experimental details}

\subsection{Materials}

Besides investigating the crack formation in Zircaloy-2, an attempt was also made to find a connection between SPP size distribution and crack formation. For this reason two different Zircaloy-2 alloys were chosen, with the main difference being their SPP size distribution. The chosen alloys are commercial alloys that have been (Material A and B), and are still (Material B), extensively used in boiling water nuclear reactors (BWRs). The two alloys have approximately the same chemical composition (Table 1), aside from a small difference in iron and tin content, but differ in final heat treatment and thereby SPP size distribution. Material A has smaller but more SPPs while Material B has larger but fewer SPPs. There are two different families of SPPs in Zircaloy-2, $\mathrm{Zr}(\mathrm{Fe}, \mathrm{Cr})_{2}$ and $\mathrm{Zr}_{2}(\mathrm{Fe}, \mathrm{Ni})$. Since $\mathrm{Fe}, \mathrm{Cr}$ and $\mathrm{Ni}$ have very low solubility in the metal matrix [32-36] and the $\mathrm{Fe} / \mathrm{Cr}$ and $\mathrm{Fe} / \mathrm{Ni}$ ratios are known $[25,37,38]$, the volume fraction of SPPs can be calculated from the given chemical composition. The volume fraction of SPPs in Material A is $1.3 \%$ and in Material B 1.6 \%. More details on the materials can be found in Ref. [25]. The size distributions are presented later on, in the Results section. 
The materials, in the form of $5 \mathrm{~cm}$ tube samples, were oxidized in static steam autoclaves at temperatures of 400 and $415^{\circ} \mathrm{C}$ (where the higher temperature was used for obtaining thick oxides within a reasonable time frame) and a pressure of $10.3 \mathrm{MPa}$ from 3 to 150 days in order to obtain oxide thicknesses of roughly 1, 2 and $9 \mu \mathrm{m}$ (Table 2). These testing conditions are standard for testing of BWR materials. From Table 2 and Fig. 1 (top) it is apparent that Material B, with the larger SPPs, has the superior oxidation behavior. The observed difference in oxidation behavior does not only apply to autoclave testing, but is also valid in reactor, as can be seen in Fig. 1 (bottom).

\subsection{TEM}

The main instrument for investigation has been TEM, where imaging has been performed using both conventional bright field TEM (with a Philips CM200 microscope) and high angle annular dark field (HAADF) imaging, giving atomic number contrast (with an FEI Tecnai T20 microscope).

The TEM thin foil specimens were prepared with an FEI Strata 235 Dual Beam workstation, using the FIB-SEM in situ lift-out technique, commonly used for producing site-specific specimens with large electron transparent areas. For more details on specimen preparation, see Ref. [25]. These specimens provide a good overview of several micrometers of the oxide and the oxide/metal interface. The TEM specimens for measuring the SPP size distribution in Material A, however, were prepared using electropolishing.

All TEM specimens were prepared along the grinding marks in the tangential direction of the tubes. However, judging from the 3-dimensional reconstructions of the oxide/metal interface performed by $\mathrm{Ni}$ et al. [23], the morphology of the lateral cracks and the oxide/metal interface is very similar in all directions along the tube surface.

\subsection{SEM}


SEM imaging was performed of oxide surface plane view samples using the secondary electron (SE) detector in a Leo Ultra 55 FEG SEM.

Samples for SEM investigations of oxide interfaces were prepared by removing the metal from the oxide, thus exposing the morphology of the oxide/metal interface. The first step in preparing these samples was cutting out small pieces $(\sim 3 \times 3 \mathrm{~mm})$ from the tubes. These samples were then ground from the tube inside in order to remove the oxide grown on the inside of the tube, and also most of the metal, leaving only a thin $(\sim 0.4 \mathrm{~mm})$ layer of metal attached to the (outer) oxide scale. Finally the samples were etched using a solution of $15 \%$ bromine in methanol until only small flakes of oxide remained, with all the metal dissolved. These flakes were then attached to SEM sample holders using carbon tape.

\section{Results}

\subsection{SPP size distributions}

Data from TEM measurements of the SPP size distribution for the same lot of Material B as studied in this work were provided by the manufacturer. For Material A no data were available for the studied lot, so the size distribution was determined, also using TEM. The measured size distributions and mean SPP sizes are displayed in Fig. 2. The measured mean SPP diameter of Material A, $21 \mathrm{~nm}$, is substantially smaller than that of Material B, $76 \mathrm{~nm}$.

However, measuring particle diameters from observations of TEM micrographs means underestimating the true diameter, due to truncation of the particles in the thin foil. More accurate estimates of mean SPP diameters were obtained by using a foil thickness correction factor [40]. The corrected mean SPP diameters were calculated to 22 and $84 \mathrm{~nm}$, respectively.

\subsection{Interface morphology}


The interfaces that have been investigated in TEM studies are $\sim 10 \mu \mathrm{m}$ wide twodimensional representations of a large three-dimensional structure. In previous SEM studies of the oxide layer on different zirconium alloys it was reported that the oxide displayed a cauliflower-like structure [26,41,42], with larger structures (typically 20 $\mu \mathrm{m})[26,41,43]$ made up by smaller ones $[14,26,43]$. This might cause a problem when studying smaller areas using TEM, as they might not be representative for the whole structure of the oxide/metal interface. For this reason a plane view SEM study of the interface topography was undertaken in this work. The result for Material A is displayed in Fig. 3, and Material B exhibits a very similar structure. The oxide/metal interfaces do not show the previously observed cauliflower structure, but rather appear quite smooth on a larger scale.

Since the oxide/metal interface is smoothly wavy in structure, the two-dimensional images and investigations can be considered representative for the whole interfacial structure. It has previously been confirmed that there is no difference in the undulations of the interface between the metal and a $1 \mu \mathrm{m}$ thick oxide scale in Materials A and B; they both show a periodicity of around $1 \mu \mathrm{m}$ and an amplitude of around $100 \mathrm{~nm}$ [25]. Fig. 4 shows the morphology of the oxide/metal interface below oxides of 1,2 and $9 \mu \mathrm{m}$. It is apparent that the amplitude of the interface undulations is larger in the $2 \mu \mathrm{m}$ sample than in the $1 \mu \mathrm{m}$ one. However, the sample with a $9 \mu \mathrm{m}$ oxide scale does not show significantly larger amplitude than the two samples with thinner oxide scales.

\subsection{Quantification of cracks}

In order to facilitate comparison with previous studies, the volume fraction of cracks in both materials was estimated, using point counting in TEM micrographs. The result is shown in Table 3. Worth noticing is that the volume fraction is higher in Material A than in Material B, and also that the volume fraction increases with increasing oxide thickness.

Since the cracks are not evenly distributed it is necessary to investigate the entire oxide scale when performing quantifications. In the specimens with $9 \mu \mathrm{m}$ thick oxide 
this was not possible, as it proved too difficult to prepare TEM thin foils that contain the whole oxide scale. For this reason there are no results for Material A, and for Material B the results are a combination of one TEM specimen from close to the oxide/metal interface and one from the outer part of the oxide. The statistics for the 9 $\mu \mathrm{m}$ oxide are poor, but the results are still presented here.

In order to correlate the number of cracks to the number of SPPs, the volume number density of cracks $N_{V, C}$ in the two materials was determined. For this reason the area number density $N_{A, C}$ and mean crack length $L$ were measured in TEM micrographs. A correction for truncation in TEM thin foils was performed in a similar manner as for the mean SPP diameters. Assuming that the cracks are of uniform size, circular and perpendicular to the foil surface, and that all cracks with their centers within the foil, or less than the circle radius outside the foil, can be detected in the micrographs, the same type of correction factors as for mean SPP diameter can be used. The corrected values of mean crack length $L_{\text {corr }}$ are displayed in Table 3. Again, there are no results for Material A with $9 \mu \mathrm{m}$ thick oxide and the results for Material B with $9 \mu \mathrm{m}$ oxide come from two TEM samples, due to the reasons mentioned above. From these values the volume number density was calculated using the equation:

$N_{V, C}=N_{A, C} /\left(t+L_{c o r r}\right)$

where $t$ is the foil thickness $(\sim 100 \mathrm{~nm})$, and $L_{\text {corr }}$ is the corrected crack length. The calculated volume number densities are displayed in Table 3.

The volume number density of SPPs $N_{V, P}$ in the two materials, was also calculated, using the equation:

$N_{V, P}=N_{A, P} /\left(t+d_{c o r r}\right)$,

where $N_{A, P}$ is the area number density of SPPs, $t$ is the foil thickness $(\sim 100 \mathrm{~nm})$, and $d_{\text {corr }}$ is the corrected mean SPP diameter (22 and $84 \mathrm{~nm}$, respectively). The measured SPP area number densities $N_{A, P}$ and the calculated SPP volume number densities $N_{V, P}$ are displayed in Table 4. 
In order to estimate the impact of the cracks on the oxidation process, the amount of crack area per oxide volume was calculated, by the equation:

$($ crack area $) /($ oxide volume $)=A_{C} \times N_{V, C}=\left(\pi L_{\text {corr }}^{2} / 4\right) \times N_{V, C}$,

where $A_{C}$ is the mean crack area of a circular crack with the diameter $L_{c o r r}$. The calculated values of crack area per volume are shown in Table 3.

\section{Discussion}

\subsection{Interface morphology}

The oxidation rate for the specific materials in the present study has not been monitored with small enough time intervals to determine when the first transition occurs, i.e. the end of the first and the start of the second $t^{1 / n}(n \approx 3)$ growth period, but for Zircaloy-2 in general the first transition occurs at around 2.5-3 $\mu \mathrm{m}$ oxide thickness during autoclave testing [44]. This means that the samples oxidized to 1 and $2 \mu \mathrm{m}$ oxide thickness are both pre-transition, but the latter is close to transition. The samples with $9 \mu \mathrm{m}$ thick oxide scales have gone through more than one transition.

There is a difference in amplitude of the oxide/metal interface undulations in materials with different oxide thicknesses. This is obvious from Fig. 4, and it has also been reported in the literature that the amplitude increases up until transition, where it decreases drastically and the process starts over again until the next transition [23,44]. This means that the undulation amplitude does not continue to increase monotonically during oxidation, but rather increases and decreases in a cyclic manner. In good agreement with this reasoning it was found that the undulations under the thickest oxide scales $(9 \mu \mathrm{m})$ were not vastly different from the ones under thinner oxide scales (Fig. 4).

\subsection{Quantification of cracks}


This study was performed on TEM specimens, which are rather time consuming to prepare, and only a few specimens were prepared from each material and oxide thickness. The statistics are thus poor compared to e.g. studies performed using the FIB slice-and-view technique, where a much higher number of cracks can be imaged and analyzed. Therefore a comparison has been made to such a study, performed by $\mathrm{Ni}$ et al. [23], to evaluate the validity of our results. In that study the niobiumcontaining alloy ZIRLO $^{\mathrm{TM}}$ was studied. ZIRLO $^{\mathrm{TM}}$ is a common alloy used in pressurized water reactors (PWRs) today, and Material B is the most common alloy used in BWRs. As can be seen in Fig. 1, ZIRLO ${ }^{\mathrm{TM}}$ and Material B exhibit a similar oxidation behavior during autoclave corrosion testing. A comparison of the crack volume fraction of these two materials therefore seems reasonable. For ZIRLO ${ }^{\mathrm{TM}}$ with $2 \mu \mathrm{m}$ oxide the crack volume fraction was $1.5 \%$ for the pre-transition part of the sample, to be compared with the crack volume fraction of Material B with $2 \mu$ m oxide thickness, which was measured to $1.7 \%$ (Table 3). It thus seems that the method used in the present study is sufficiently accurate for making estimations and quantifications concerning cracks. It is also satisfying that FIB-SEM slicing and TEM thin foils gave approximately the same result, since a thin foil can be expected to be more sensitive to release of residual stresses than a cross-section of a bulk specimen.

The most obvious difference when studying TEM micrographs of Material A and B is that Material A has many more cracks (Fig. 5). This has been reported qualitatively before [25] and can now also be confirmed by quantification of cracks, as both crack volume fraction and volume number density are higher for Material A than Material B. Since the only real difference between the two materials is their size distribution of SPPs, a correlation of the number density of cracks to the number density of SPPs has also been performed, see the Crack nucleation section below.

\subsection{The origin of the lateral cracks}

Oxidation of zirconium and its alloys takes place by inward diffusion of oxygen. When the first thin layer of oxide is created, diffusion proceeds by grain boundary diffusion in zirconia, since bulk diffusion through the oxide grains is much slower at 
the current temperatures $[46,47]$. Parise et al. have modeled this grain boundary diffusion at $340^{\circ} \mathrm{C}$, but the mechanisms should be the same for $400^{\circ} \mathrm{C}$, only the rates might differ slightly. They found from the literature that the measured diffusion coefficient, $D$, for zirconia varies significantly in different studies, in the range of approximately $10^{-14}$ to $10^{-15} \mathrm{~cm}^{2} \mathrm{~s}^{-1}$, with a mean value of $4.2 \times 10^{-15} \mathrm{~cm}^{2} \mathrm{~s}^{-1}$. In addition, a decrease of $D$ with decreasing oxygen content in the oxide had been found, down to an oxygen content of about 50 at. \%, below which the same low diffusion constant as in the metal had been found $\left(9.25 \times 10^{-18} \mathrm{~cm}^{2} \mathrm{~s}^{-1}\right)$. They therefore assumed that the diffusion rate varies between different grain boundaries, i.e. it is not homogeneous. They modeled the oxygen diffusion, assuming $20 \mathrm{~nm}$ wide columnar oxide grains. A variation of a factor of 10 above and below the mean value for $D$ was randomly assigned to each grain boundary in the oxide scale, under the condition that no bulk diffusion or diffusion at the oxide/metal interface takes place. The conclusion was that the inhomogeneous diffusion rate gives rise to the characteristic wavy interface that can be observed for oxidized zirconium alloys [48].

According to their model, the wavelength of the undulations should be essentially independent of original metal surface and alloy chemistry, as soon as the oxide is columnar with about the same small column width. This was also observed previously for Material A and B with $1 \mu \mathrm{m}$ thick oxide, where a nearly constant wavelength of about $1 \mu \mathrm{m}$ was found in both cases [25].

Given that the interface is undulating and that the creation of oxide gives rise to a 1.55 times volume increase [49], the stresses in the oxide and the metal can be modeled. Parise et al. have performed such modeling, based on a linear expansion of 54\% perpendicular to the oxide/metal interface (in the radial direction of a tube) and $0.5 \%$ in the two directions parallel to the interface (tangential and axial directions of a tube). They showed that there are large local stresses in the oxide perpendicular to the interface, tensile stresses above wave crests (the less-deeply oxidized regions of the interface) and compressive stresses in between [50].

A simple diagram showing the expansion of the volume of metal above a wave valley is shown in Fig. 6. The volume of metal between A and B is oxidized and has therefore expanded 54\% until C. At the wave crest (D) no oxidation has yet occurred. 
If the metal could deform under a negligible stress (like a liquid) no stress perpendicular to the interface would be created. However, the metal requires a high stress to deform, and large compressive stresses perpendicular to the interface will be created at wave valleys both in oxide and metal. At wave crests large tensile stresses will be created perpendicular to the interface, locally above $800 \mathrm{MPa}$ in the oxide as calculated by Parise et al. [49]. Parallel to the interface, compressive stresses exist in the oxide and tensile stresses in the metal due to the much smaller expansion $(0.5 \%)$ along the interface. In good agreement with this result, lateral cracks can indeed be seen preferentially above wave crests, a result found both by modeling [51] and SEM observations $[14,23]$. The conclusion is that these tensile stresses perpendicular to the oxide/metal interface make cracking of the oxide in the lateral direction possible.

Other studies have suggested somewhat similar theories for crack formation, although without realizing the reasons for and the magnitude of the local stresses perpendicular to the interface $[9,23]$.

\subsection{Crack nucleation}

In order for a crack to form, not only a driving force in the form of a tensile stress is required, but also a nucleation site. We have previously suggested a mechanism for crack initiation at SPPs, where the absence of volume increase that stems from the lower oxidation rate of SPPs compared to the surrounding metal matrix initiates the formation of voids and cracks (Fig. 7) [25]. Thus, crack nucleation requires the combination of a high stress field and the presence of an SPP, i.e. the SPP must be located within the high stress field.

Parise et al. show that the highest tensile stresses (800 MPa) are only found in a small volume in the very vicinity of a wave crest. This volume has the shape of a cylinder with the approximate radius of $100 \mathrm{~nm}$ and height of $50 \mathrm{~nm}$, i.e. a volume of $1.6 \times 10^{-3}$ $\mu \mathrm{m}^{3}$ (values approximated from stress distribution plots) [50]. Within this volume there should statistically be $1.6 \times 10^{-3} \times N_{V, P}$ particles. This means that in Material A (with $N_{V, P}=560 / \mu \mathrm{m}^{3}$ ) there are 0.90 particles in each high stress volume, and in Material B (with $N_{V, P}=39 / \mu \mathrm{m}^{3}$ ) 0.06 particles. In Material A there should therefore 
approximately be one crack located on top of every wave crest, while in Material B only one crack in 15 wave crests.

When studying cracks above wave crests using TEM, a difference can be seen between the two materials. However, the difference does not appear to be as large as the factor of 15 mentioned here. Indeed the crack number densities presented in Table 4 reveal that the difference is not a factor of 15 but a factor in the range 2.5-4 for the two different oxide thicknesses.

Thus, it is apparent that not every SPP can be associated with a crack being formed. There are two reasons for this:

1. Not all SPPs are large enough to initiate a crack; there must be a critical SPP size for crack initiation. This fact will affect Material A the most, as this material has smaller SPPs.

2. The stress situation above a wave crest varies as the oxidation proceeds: Once a crack has been created, the stress is relieved and no more driving force exists for crack nucleation. The oxide front has to move some distance inwards before the tensile stress is again built up and a new crack can be formed.

In conclusion, the following correlation has been found between a high number density of SPPs and a high number density of cracks: As the oxide layer grows inwards it will crack more often in the high-stress regions close to the interface if the number density of SPPs is high, and these cracks will remain in the oxide also when the oxidation front moves deeper and the stress level around them has decreased, leading to more cracks in a material with more SPPs.

\subsection{Impact of cracks on the oxidation process}

It has previously been shown that the outer part of the oxide is rather porous, and that the innermost oxide layer is the most important part with regard to corrosion resistance. Therefore it is of interest to understand the impact of the cracks in the inner oxide layer on the oxidation process. Ni et al. [23] suggest that the cracks act as obstacles for the diffusion path, slowing down the diffusion rate. However, we rather 
believe that the cracks act as short-circuits for the diffusion paths, thus increasing the diffusion rate. This reasoning is based on the well-known fact that surface diffusion is much faster than grain boundary diffusion, which in turn is much faster than bulk diffusion [52]. This means that oxygen diffusion through the oxide takes place in grain boundaries rather than by bulk diffusion, and as the oxygen reaches a crack it will quickly diffuse along the periphery of the crack, i.e. by surface diffusion. This way the diffusion underneath the crack can proceed in a grain boundary that allows for fast diffusion. Thus, although the diffusion path through the crack is longer, the diffusion rate is still higher.

If this is the case, the mean crack area per oxide volume should be an interesting factor. This ratio was calculated, and the values are found in Table 3. For samples with $1 \mu \mathrm{m}$ oxide thickness, the difference between the two materials is around a factor of $2(0.37 / 0.21)$, while for the thicker oxide scale of $2 \mu \mathrm{m}$, the ratio between the materials is roughly a factor of $3(1.25 / 0.43)$. However, according to the reasoning above, the most relevant number is that of the thinner oxide samples, since the outer parts of the thicker oxide are already transparent for oxygen diffusion, and not a limiting factor. So, according to these calculations, the probability for the diffusing oxygen to find a grain boundary with a high diffusion constant through the innermost, dense oxide layer might be twice as high in Material A as in Material B.

\subsection{Transition in oxidation rate}

It is a well-known fact that there is a transition in the oxidation kinetics occurring at an oxide thickness of approximately $2-3 \mu \mathrm{m}$, depending on alloy type. This transition is associated with the creation of large continuous lateral cracks, but the driving force for the growth of the cracks is not established. In the present work mainly pretransition oxides have been studied. Thus, it is difficult to draw any conclusions about what happens at transition. However, the following scenario seems likely: Due to the high stresses and small grain size in the oxide close to the oxide/metal interface, tetragonal oxide is stabilized to some extent in this area $[13,15]$. However, the stresses in the oxide decrease with increasing distance to the oxide/metal interface $[13,48,50]$, causing the tetragonal oxide grains to transform into monoclinic grains. Since these grains are larger there will be a substantial increase in the stress levels as this 
transformation occurs, causing the existing cracks to propagate and form a continuous band of large cracks. At this point the oxide is no longer protective and the corrosion kinetics start over again.

\subsection{Comparison with reactor data}

This study is based on materials tested in autoclave, and the results are not necessarily valid also for materials oxidized in a reactor. Also, there is a difference in the time scales of the autoclave and in-reactor data presented in Fig. 1, so a comparison of the two is difficult to make. However, despite the different conditions, the mechanisms concerning crack formation should be similar both in autoclave and in reactor. Also, in both cases Material B exhibits the superior corrosion behavior, showing that the SPP size distribution is an important parameter.

The SPPs increase the oxidation rate by facilitating oxygen diffusion, and thus Material A has a poorer corrosion resistance due to the more numerous SPPs. However, the SPPs are also needed, as the cracking caused by them helps relax the stresses in the oxide. Without SPPs much larger stresses would be built up until large cracks would be created, perhaps leading to spalling of the oxide and a much poorer corrosion resistance. After some time in the reactor, the SPPs start to dissolve, and the beneficial effect from them decreases. Thus, in a material with larger SPPs the effect will last longer as it takes longer time for the SPPs to dissolve. However, the SPPs cannot be too large, as this leads to nodular corrosion [53].

\section{Conclusions}

The formation of lateral cracks in the oxide scales of zirconium alloys is an important parameter influencing the oxidation process. While other mechanisms might also be present, the main mechanism for crack initiation has been presented in this paper. This mechanism is summarized below, based on previous studies and the new results from the present investigation:

- The oxide formed on Zircaloy-2 consists mainly of columnar grains of monoclinic $\mathrm{ZrO}_{2}$.

- Diffusion of oxygen takes place in the oxide grain boundaries, but the diffusion rate varies between different grain boundaries. Thus, diffusion is inhomogeneous, i.e. 
oxygen reaches the metal at different rates in different locations, which leads to the creation of an undulating oxide/metal interface.

- Such an undulating interface gives rise to large stresses in the direction of the oxide growth, i.e. perpendicular to the interface, with tensile stresses above wave crests and compressive stresses in between.

- The tensile stresses above wave crests cause lateral cracks to form preferentially in these locations.

- SPPs act as nucleation sites for cracks, since a void is created above each SPP due to the absence of volume increase caused by the delayed oxidation of SPPs compared to the metal matrix.

Also, it has been shown that there is a link between the difference in SPP size distribution and the number of cracks. This finding is in good agreement with the proposed mechanism for crack nucleation at SPPs.

The impact of the lateral cracks on the oxidation process is suggested to be to help connect the diffusion paths for oxygen. It is suggested that part of the explanation for the higher oxidation rate of Material A compared to Material B (both in autoclave and in-reactor) is easier ingress of oxygen due to more lateral cracks. Therefore the amount of lateral cracks can be considered as one important factor in the oxidation process of zirconium alloys.

\section{Acknowledgements}

Sandvik Materials Technology is thanked for supplying the materials and performing the autoclave testing. This work was carried out with the support of Westinghouse Electric Sweden AB, Sandvik AB, Vattenfall Nuclear Fuel AB, OKG AB and the Swedish Radiation Safety Authority. 


\section{References}

[1] B. Zhou, in: L.F.P. Van Swam, C. M. Eucken (Eds.), Proceedings of 8th International Symposium on Zr in the Nuclear Industry, ASTM-STP-1023, ASTM International, West Conshohocken, PA, 1989, pp. 360-373.

[2] F. Garzarolli, H. Seidel, R. Tricot, J.P. Gros, in: C.M. Eucken, A.M. Garde (Eds.), Proceedings of 9th International Symposium on $\mathrm{Zr}$ in the Nuclear Industry, ASTM-STP-1132, ASTM International, Philadelphia, PA, 1991, pp. 395-415.

[3] M. Harada, M. Kimpara, K. Abe, in: C.M. Eucken, A.M. Garde (Eds.), Proceedings of 9th International Symposium on $\mathrm{Zr}$ in the Nuclear Industry, ASTM-STP-1132, ASTM International, Philadelphia, PA, 1991, pp. 368-391.

[4] T. Kubo, M. Uno, in: C.M. Eucken, A.M. Garde (Eds.), Proceedings of 9th International Symposium on Zr in the Nuclear Industry, ASTM-STP-1132, ASTM International, Philadelphia, PA, 1991, pp. 476-498.

[5] B.D. Warr, M.B. Elmoselhi, S.B. Newcomb, N.S. McIntyre, A.M. Brennenstuhl, P.C. Lichtenberger, in: C.M. Eucken, A.M. Garde (Eds.), Proceedings of 9th International Symposium on $\mathrm{Zr}$ in the Nuclear Industry, ASTM-STP-1132, ASTM International, Philadelphia, PA, 1991, pp. 740-757.

[6] H.-J. Beie, A. Mitwalsky, F. Garzarolli, H. Ruhmann, H.-J. Sell, in A.M. Garde, E.R. Bradley (Eds.), Proceedings of 10th International Symposium on $\mathrm{Zr}$ in the Nuclear Industry, ASTM-STP-1245, ASTM International, Philadelphia, PA, 1994, pp. 615-643.

[7] B. Wadman, Z. Lai, H.-O. Andrén, A.-L. Nyström, P. Rudling, H. Pettersson, in A.M. Garde, E.R. Bradley (Eds.), Proceedings of 10th International Symposium on Zr in the Nuclear Industry, ASTM-STP-1245, ASTM International, Philadelphia, PA, 1994, pp. 579-598.

[8] J. Mayer, L. Giannuzzi, T. Kamino, J. Michael, MRS Bull. 32 (2007) 400-407.

[9] S. Abolhassani, R. Restani, T. Rebac, F. Groeschel, W. Hoffelner, G. Bart, W. Goll, F. Aeschbach, J. ASTM Int. 2, (2005) No. 6.

[10] D. Hudson, N. Ni, S. Lozano-Perez, D. Saxey, C. English, G.D.W. Smith, J. Sykes, C. Grovenor, in: Proceeedings of 14th International Conference on Environmental Degradation of Materials in Nuclear Power Systems, Virginia 
Beach, VA, August 23-27, 2009, American Nuclear Society, La Grange Park, IL.

[11] N. Ni, S. Lozano-Perez, M.L. Jenkins, C. English, G.D.W. Smith, J.M. Sykes, C. Grovenor, Scr. Mater. 62 (2010) 564-567.

[12] C. Proff, S. Abolhassani, M.M. Dadras, C. Lemaignan, J. Nucl. Mater. 404 (2010) 97-108.

[13] M. Preuss, P. Frankel, S. Lozano-Perez, D. Hudson, E. Polatidis, N. Ni, J. Wei, C. English, S. Storer, K.B. Chong, M. Fitzpatrick, P. Wang, J. Smith, C. Grovenor, G.D.W. Smith, J. Sykes, B. Cottis, S. Lyon, L. Hallstadius, B. Comstock, S. Ambard, M. Blat-Yrieix, J. ASTM Int. 8 (2011), No. 9.

[14] P. Bossis, G. Lelièvre, P. Barberis, X. Iltis, F. Lefebvre, in: G.P. Sabol, G.D. Moan (Eds.), Proceedings of 12th International Symposium on $\mathrm{Zr}$ in the Nuclear Industry, ASTM-STP-1354, ASTM International, West Conshohocken, PA, 2000, pp. 918-945.

[15] A. Yilmazbayhan, A.T. Motta, R.J. Comstock, G.P. Sabol, B. Lai, Z. Cai, J. Nucl. Mater. 324 (2004) 6-22.

[16] V. Bouineau, A. Ambard, G. Bénier, D. Pêcheur, J. Godlewski, L. Fayette, T. Duverneix, J. ASTM Int. 5 (2006), No. 5.

[17] J-Y. Park, S. Yoo, B.-K. Choi, Y. Jeong, J. Alloys Compd. 437 (2007) 274 279 .

[18] P. Bossis, J. Thomazet, F. Lefebvre, in: G.D. Moan, P. Rudling (Eds.), Proceedings of 13th International Symposium on Zr in the Nuclear Industry, ASTM-STP-1423, ASTM International, West Conshohocken, PA, 2002, pp. $190-221$.

[19] A.T. Motta, M.J. Gomes da Silva, A. Yilmazbayhan, R.J. Comstock, Z. Cai, B. Lai, J. ASTM Int. 5, (2008), No. 3.

[20] D. Pecheur, J. Godlewski, P. Billot, J. Thomazet, in: E.R. Bradley, G.P. Sabol (Eds.), Proceedings of 11 th International Symposium on Zr in the Nuclear Industry, ASTM-STP-1295, ASTM International, West Conshohocken, PA, 1996, pp. 94-113.

[21] S. Abolhassani, P. Gasser, J. Microsc. 223 (2006) 73-82.

[22] A. Yilmazbayhan, E. Breval, A.T. Motta, R.J. Comstock, J. Nucl. Mater. 349 (2006) 265-281. 
[23] N. Ni, S. Lozano-Perez, J.M. Sykes, G.D.W. Smith, C.R.M. Grovenor, Corr. Sci. 53 (2011) 4073-7083.

[24] C. Proff, S. Abolhassani, C. Lemaignan, J. Nucl. Mater. 416 (2011) 125-134.

[25] P. Tejland, M. Thuvander, H.-O. Andrén, S. Ciurea, M. Dahlbäck, L. Hallstadius, J. ASTM Int. 8 (2011), No. 6.

[26] O. Gebhardt, A. Hermann, G. Bart, H. Blank, F. Garzarolli, L. Ray, in: E.R. Bradley, G.P. Sabol (Eds.), Proceedings of 11th International Symposium on $\mathrm{Zr}$ in the Nuclear Industry, ASTM-STP-1295, ASTM International, West Conshohocken, PA, 1996, pp. 218-241.

[27] C.M. Eucken, P.T. Finden, S. Trapp-Pritsching, H.G. Weidinger, H. G., in: L.F.P. Van Swam, C. M. Eucken (Eds.), Proceedings of 8th International Symposium on Zr in the Nuclear Industry, ASTM-STP-1023, ASTM International, West Conshohocken, PA, 1989, pp. 113-127.

[28] F. Garzarolli, E. Steinberg, H.G. Weidinger, H. G., in: L.F.P. Van Swam, C. M. Eucken (Eds.), Proceedings of 8th International Symposium on $\mathrm{Zr}$ in the Nuclear Industry, ASTM-STP-1023, ASTM International, West Conshohocken, PA, 1989, pp. 202-212.

[29] F. Garzarolli, H. Stehle, E. Steinberg, E., in: E.R. Bradley, G.P. Sabol (Eds.), Proceedings of 11th International Symposium on $\mathrm{Zr}$ in the Nuclear Industry, ASTM-STP-1295, ASTM International, West Conshohocken, PA, 1996, pp. $12-32$.

[30] P. Rudling, G. Wikmark, J. Nucl. Mater. 265 (1999), 44-59.

[31] P. Barberis, E. Ahlberg, N. Simic, D. Charquet, C. Lemaignan, G. Wikmark, M. Dahlbäck, M. Limbäck, P. Tägtström, B. Lehtinen, in: G.D. Moan, P. Rudling (Eds.), Proceedings of 13th International Symposium on $\mathrm{Zr}$ in the Nuclear Industry, ASTM-STP-1423, ASTM International, West Conshohocken, PA, 2002, pp. 33-58.

[32] B. Wadman, Doctoral Thesis, Dept. of Physics, Chalmers University of Technology, Göteborg, 1993.

[33] A. Yilmazbayhan, O. Delaire, A.T. Motta, R.C. Birtcher, J.M. Maser, B. Lai, J. Nucl. Mater. 321 (2003) 221-232.

[34] B. Hutchinson, B. Lehtinen, M. Limbäck, M. Dahlbäck, J. ASTM Intl., 4 (2009), No. 10.

[35] D. Hudson, Doctoral Thesis, Oxford, UK, 2010 
[36] M. Thuvander, H.-O. Andrén, Ultramicroscopy 111 (2011) 711-714.

[37] Z. Meng, D. Northwood, J. Nucl. Mater. 168 (1989) 125-136.

[38] Y. Hatano, M. Sugisaki, J. Nucl. Sci. Technol. 33 (1996) 829-833.

[39] P. Tägtström, M. Limbäck, M. Dahlbäck, T. Andersson, H. Pettersson, in: G.D. Moan, P. Rudling (Eds.), Proceedings of 13th International Symposium on $\mathrm{Zr}$ in the Nuclear Industry, ASTM-STP-1423, ASTM International, West Conshohocken, PA, 2002, pp. 96-118.

[40] M. Hättestrand, H.-O. Andrén, Micron 32 (2001) 789-797.

[41] B. Hutchinson, B. Lehtinen, J. Nucl. Mater. 217 (1994) 243-249.

[42] G. Wikmark, P. Rudling, B. Lehtinen, B. Hutchinson, A. Oscarsson, E. Ahlberg, in: E.R. Bradley, G.P. Sabol (Eds.), Proceedings of 11th International Symposium on Zr in the Nuclear Industry, ASTM-STP-1295, ASTM International, West Conshohocken, PA, 1996, pp. 55-73.

[43] H. Blank, G. Bart, H. Thiele, J. Nucl. Mater. 188 (1992) 273-279.

[44] M. Harada, R. Wakamatsu, J. ASTM Int. 5 (2008), No. 3.

[45] P. Tejland, H.-O. Andrén, In manuscript

[46] B. Cox, C. Roy, Electrochem. Technol. 4 (1966) 121-127.

[47] J. Godlewski, J.P. Gros, M. Lambertin, J.F. Wadier, H. Weidinger, in: C.M. Eucken, A.M. Garde (Eds.), Proceedings of 9th International Symposium on Zr in the Nuclear Industry, ASTM-STP-1132, ASTM International, Philadelphia, PA, 1991, pp. 416-436.

[48] M. Parise, R. Foerch, G. Cailletaud, J. Physique IV 9 (1999) 311-320.

[49] N.B. Pilling, R.E. Bedworth, J. Inst. Met. 29 (1923) 529-591.

[50] M. Parise, O. Sicardy, G. Cailletaud, J. Nucl. Mater. 256 (1998) 35-46.

[51] A. Ly, A. Ambard, M. Blat-Yrieix, L. Legras, P. Frankel, M. Preuss, C. Curfs, G. Parry, Y. Bréchet, J. ASTM Int. 8 (2011), No. 9.

[52] D.A. Porter, K.E. Easterling, Phase Transformations in Metals and Alloys, second ed., Chapman \& Hall, London, 1992

[53] F. Garzarolli, H. Stehle, E. Steinberg, in: E.R. Bradley, G.P. Sabol (Eds.), Proceedings of 11 th International Symposium on $\mathrm{Zr}$ in the Nuclear Industry, ASTM-STP-1295, ASTM International, West Conshohocken, PA, 1996, pp. $12-32$. 


\section{Tables}

Table 1. Chemical composition of the two studied Zircaloy-2 materials (mass \%).

\begin{tabular}{|c|c|c|}
\hline Element & Material A & Material B \\
\hline Sn (\%) & 1.46 & 1.32 \\
Fe (\%) & 0.12 & 0.17 \\
Cr (\%) & 0.10 & 0.10 \\
Ni (\%) & 0.05 & 0.05 \\
Si (ppm) & 80 & 70 \\
O (ppm) & 1240 & 1300 \\
N (ppm) & 40 & 50 \\
\hline
\end{tabular}

Table 2. Autoclave data and the resulting weight gains and corresponding oxide thicknesses (calculated assuming that $15 \mathrm{mg} / \mathrm{dm}^{2}$ corresponds to $1 \mu \mathrm{m}$ ).

\begin{tabular}{|c|c|c|c|c|}
\hline Alloy & $\begin{array}{c}\text { Temp } \\
\left({ }^{\circ} \mathrm{C}\right)\end{array}$ & $\begin{array}{c}\text { Time } \\
(\mathrm{days})\end{array}$ & $\begin{array}{c}\text { Weight gain } \\
\left(\mathrm{mg} / \mathrm{dm}^{2}\right)\end{array}$ & $\begin{array}{c}\text { Oxide thickness } \\
(\mu \mathrm{m})\end{array}$ \\
\hline Material A & 400 & 3 & 18.9 & 1.3 \\
& 400 & 6 & 33.9 & 2.3 \\
& 415 & 30 & 132.5 & 8.8 \\
\hline Material B & 400 & 3 & 15.0 & 1.0 \\
& 400 & 15 & 27.5 & 1.8 \\
& 415 & 150 & 135 & 9.0 \\
\hline
\end{tabular}


Table 3. Investigated oxide area, number of cracks, volume fraction of cracks $\left(f_{V}\right)$, measured mean crack length $(L)$, corrected mean crack length $\left(L_{c o r r}\right)$, area number density $\left(N_{A, C}\right)$, volume number density $\left(N_{V, C}\right)$, mean crack area $\left(A_{C}\right)$ and crack area per oxide volume $\left(A_{C} \times N_{V, C}\right)$ for both materials with different oxide thicknesses.

\begin{tabular}{|l|c|c|c|c|c|c|}
\hline Alloy & \multicolumn{3}{|c|}{ Material A } & \multicolumn{3}{c|}{ Material B } \\
\hline Oxide thickness $(\mu \mathrm{m})$ & 1 & 2 & 9 & 1 & 2 & 9 \\
Oxide area $\left(\mu \mathrm{m}^{2}\right)$ & 11.0 & 11.8 & - & 33.5 & 12.0 & 22.9 \\
No of cracks & 20 & 39 & - & 20 & 13 & 58 \\
$f_{V}(\mathrm{vol} \%)$ & 3.1 & 5.7 & - & 0.4 & 1.7 & $2.8^{*}$ \\
$L(\mathrm{~nm})$ & 281 & 458 & - & 421 & 460 & $317^{*}$ \\
$L_{c o r r}\left(\mathrm{~nm}^{2}\right)$ & 337 & 563 & - & 518 & 565 & $380^{*}$ \\
$N_{A, C}\left(\mu \mathrm{m}^{-2}\right)$ & 1.8 & 3.3 & - & 0.6 & 1.1 & $2.5^{*}$ \\
$N_{V, C}\left(\mu \mathrm{m}^{-3}\right)$ & 4.1 & 5.0 & - & 1.0 & 1.7 & $5.2^{*}$ \\
$A_{C}\left(\mu \mathrm{m}^{2}\right)$ & 0.09 & 0.25 & - & 0.21 & 0.25 & - \\
$A_{C} \times N_{V, C}\left(\mu \mathrm{m}^{2} / \mu \mathrm{m}^{3}\right)$ & 0.37 & 1.25 & - & 0.21 & 0.43 & - \\
\hline
\end{tabular}

*Average value of two TEM foils; one close to the oxide/metal interface and one from the outer part of the oxide scale.

Table 4. SPP area number density $\left(N_{A, P}\right)$ and volume number density $\left(N_{V, P}\right)$.

\begin{tabular}{|l|c|c|}
\hline Alloy & $N_{A, P}\left(\mu \mathrm{m}^{-2}\right)$ & $N_{V, P}\left(\mu \mathrm{m}^{-3}\right)$ \\
\hline Material A & 5.4 & 560 \\
Material B & 16.6 & 39 \\
\hline
\end{tabular}




\section{Figure captions}

Figure 1. Oxidation behavior of Material A, Material B and ZIRLO ${ }^{\mathrm{TM}}$ during autoclave corrosion testing (top) and of Material A and Material B in reactor (bottom). Bottom image after [39].

\section{(COLOR ON THE WEB, BLACK-AND-WHITE IN PRINT)}

Figure 2. SPP size distributions in Material A and B, measured using TEM.

Figure 3. Plane view SEM images of the surface topography of Material A with (a) 1 $\mu \mathrm{m}$ and (b) $9 \mu \mathrm{m}$ oxide thickness.

Figure 4. Oxide/metal interface undulations in Material B under (a) $1 \mu \mathrm{m}$, (b) $2 \mu \mathrm{m}$ and (c) $9 \mu \mathrm{m}$ oxide thickness. The inversed contrast in the images comes from using SEM with an annular dark field (ADF) detector in (a) and TEM with a high angle annular dark field (HAADF) detector in (b) and (c), both giving atomic number contrast but using different energies. The acicular shaped precipitates seen in (a) are hydrides [45].

Figure 5. Bright field TEM images of (a) Material A and (b) Material B, both with 1 $\mu \mathrm{m}$ oxide, showing the difference in crack density.

Figure 6. (a) Diagram showing the expansion of the volume of metal above a wave valley. When the volume of metal between A and B oxidizes, it will expand 54\% until C. At D no oxidation has yet occurred. If the metal could deform under a negligible stress (like a liquid) no stress perpendicular to the interface would be created. (b) Since the metal requires a high stress to deform, large compressive stresses perpendicular to the interface will be created at wave valleys both in oxide and metal. At wave crests large tensile stresses will be created. Parallel to the interface, compressive stresses exist in the oxide and tensile stresses in the metal due to the much smaller expansion (0.5\%) along the interface. Fig. 6 (b) redrawn after [49]. 
Figure 7. Schematic diagram of void and crack formation at SPPs. When the metal layer between the full and dashed line in (a) oxidizes, it expands perpendicular to the interface and forms the layer between the dashed and full line in (b). Since the SPPs are not oxidized, a void (left) is formed or, if the oxide first adheres to the SPP, a crack in the oxide and a smaller void form (right). After [25]. 